\title{
What Leads to Evocation of Moral Outrage? Exploring the Role of Personal Morality
}

\author{
Shunsuke Uehara ${ }^{1}$, Tomohiro Nakagawa ${ }^{2} \&$ Toru $_{\text {Tamura }}{ }^{3}$ \\ ${ }^{1}$ Graduate School of Arts and Letters, Tohoku University, Sendai, Japan \\ ${ }^{2}$ Faculty of Applied Sociology, Kinki University, Higashi-Osaka, Japan \\ ${ }^{3}$ Faculty of Social Welfare, Iwate Prefectural University, Iwate, Japan \\ Correspondence: Shunsuke Uehara, Department of Psychology, Graduate School of Arts and Letters, Tohoku \\ University, Kawauchi 27-1, Aoba Ward, Sendai 980-8576, Japan. Tel: 81-22-795-6048. E-mail: \\ uehara_s@m.tohoku.ac.jp
}

Received: December 25, 2013

Accepted: January 17, $2014 \quad$ Online Published: January 24, 2014

doi:10.5539/ijps.v6n1p58

URL: http://dx.doi.org/10.5539/ijps.v6n1p58

\begin{abstract}
Anger is usually evoked when an individual perceives that his/her moral standard or principle has been violated. This has been termed as "moral outrage." However, some researchers have suggested that anger at an immoral act is personal because increased anger was reported only when harm was undeservedly inflicted upon the self or an in-group member even if the act was judged to be a moral violation. In this study, on the basis of the assumption that moral outrage is a conditional emotional reaction that is evoked only in individuals high in morality, we attempted to examine whether personal morality elicited moral outrage. Japanese participants were asked to read a fictitious newspaper article describing a case of abduction. The abducted victim was described as Japanese for half of the participants, and as Slovenian for the other half. Immediately after reading the article, anger, the perception of the wrongness of the abduction, and personal morality was assessed. We found that anger was increased only in the Japanese abductee condition, regardless of whether the level of self-reported morality was low or high. We discuss the possibility that personal anger is an exceedingly prevalent emotion and the question as to why no evidence of moral outrage was found.
\end{abstract}

Keywords: anger, moral outrage, personal anger, morality

\section{Introduction}

The topic of how individuals respond to immoral events or acts has been of great interest to social psychologists. Some researchers consider that individuals respond to moral violations by taking actions to restore a sense of fairness. It is assumed that to restore fairness or justice, individuals take actions toward re-establishing or reaffirming the violated moral standards by punishing harm-doers or by compensating victims. Contrary to this assumption, however, the findings of social psychological research show that people often fail to take action intended to restore fairness. For example, they may remain as bystanders in the events involving moral violations (Latané \& Darley, 1970) or blame the victim (Correia \& Vala, 2003) in order to rationalize a lack of response (Tsang, 2002). These findings that it is extremely difficult for people to take fairness-restoring actions against violation of a moral standard suggest that there is an urgent need to identify psychological factors prompting such actions.

A wide variety of factors can lead people to take actions intended to restore fairness against moral violations; emotional factors are likely to contribute to the expression of such actions. One emotional factor that is expected to evoke fairness-restoring behavior is moral outrage. Moral outrage refers to anger provoked by the perception that a moral standard or principle has been violated irrespective of the identity of the victim (Batson, Chao, \& Givens, 2009; Batson et al., 2007; Darley \& Pittman, 2003; O’Mara, Jackson, Batson, \& Gaertner, 2011). Moral outrage is not only involved in moral or ethical values but it is also regarded as a potent source of moral motivation, prompting efforts to restore fairness, such as punishment of the harm-doer, compensation to the victim, or a request for an apology (Barclay, Skarlicki, \& Pugh, 2005; de Rivera, Gerstmann, \& Maisels, 2002; Tetlock, Kristel, Elson, Green, \& Lerner, 2000). 


\subsection{Evidence of Other Possible Form of Anger}

However, some researchers doubt whether anger is evoked only by a sense of justice because to be violated often also involves infliction of harm upon the self (or the possibility of such harm), such as thwarting one's own interests, personal insult, etc. This implies that in some cases, fairness-restoring behavior may be provoked by the activation of egoistic goals due to anger. What specific forms of anger are evoked in the contexts where fairness-restoring behavior might be expected?

Batson and his colleagues (Batson et al., 2007) conducted an experimental manipulation in which $\$ 30.00$ worth of raffle tickets were unequally allocated (self vs. stranger). The participants were then asked to report their feelings of anger. The results showed that while all participants judged the unequal allocation of tickets as unfair or immoral, only when the victim of unequal allocation was the self did it provoke more anger. In another experiment about anger evoked owing to harm done to an in-group member (Batson et al., 2009), American undergraduates were asked to read a fictitious newspaper article describing the torture of a U.S. Marine (vs. a Sri Lankan soldier). The results show that intense anger was evoked only about the knowledge of the U.S. Marine being tortured, although torture was judged by all of them to be morally wrong in all experimental conditions. Using a measure of behavioral as well as an emotional response, O'Mara et al. (2011) manipulated a victim who was excluded; this study revealed that respondents reported less anger or allocated more money to the exclusion instigator after witnessing a stranger being excluded than after being excluded themselves (indicative of punishment). Similarly, Lieberman and Linke (2007) asked participants to imagine an incident in which a person was robbed, and found that they perceived this robbery as wrong regardless of the type of victim (Experiment 2); however, they were far more likely to report anger when the victim was kin than when he/she was a stranger (Experiment 3).

These empirical findings suggest that in the context of moral violation, moral outrage is unlikely to be virtually evoked. In particular, the findings that anger is evoked only when harm is inflicted upon the self or an in-group member, despite the harm being judged as a moral violation, imply that anger largely involves egoistic concerns independently of moral sense, which are phrased as "the way it should be." The anger that a person might feel when the person or in-group member's own interests are thwarted is called personal anger, which leads researchers to re-examine the form of anger.

However, it can be assumed that the emotion of moral outrage is yet to be properly examined and may actually be a dispositional response experienced only by certain people. Anger is usually evoked only by negative judgments without any experience of personal harm, which implies that anger is provoked precisely because of the individuals' high moral values such as justice or sense of fairness. In this study, we focused on the dispositional determinant of individuals who have a sense of morality, and attempted to examine the effect of this dispositional determinant on the evocation of moral outrage.

\subsection{Moral Outrage and Personal Morality}

Although many researchers focusing on morality have discussed that individuals having a strong sense of morality experience moral outrage (e.g., Heider, 1958; Hoffman, 1987), the association between personal morality and moral outrage has not been demonstrated empirically. However, there is some suggestive evidence. Schmitt and his colleagues found that respondents reporting relatively high morality were likely to perceive unfair treatment more frequently (Schmitt, Neumann, \& Montada, 1995), and thus, they were motivated to restore fairness (Mohiyeddini \& Schmitt, 1997; Schmitt \& Mohiyeddini, 1996) and punish the harm-doer even when their own interests were thwarted (Fetchenhauer \& Huang, 2004). Moreover, it was found that procedurally unfair treatment at work was likely to decrease job satisfaction among those with high morality (Schmitt \& Dörfel, 1999).

We now propose that the personal morality is the significant dispositional determinant producing moral outrage. As mentioned above, to the extent that individuals have a sense of morality, they will be unable to overlook the violation of moral standards, be more sensitive to these events, and feel a profound sense of obligation to right the wrong whenever harmed undeservedly. Since they prefer to implement the right action from a moral or ethical perspective, it is likely to be difficult for them to tolerate immoral acts even when the self is not harmed. On this basis, we predicted that when individuals high in personal morality witness or experience an immoral treatment, they are likely to feel moral outrage because they perceive the treatment itself to be unforgivable irrespective of whether they themselves (or a member of their in-group) or another person are the victims. 


\subsection{The Present Research}

To test these predictions, we adopted Batson's experimental paradigm, which is based on appraisal theory, in which emotional reactions are determined by different cognitive appraisals of the situation (e.g., Forgas, 1992; Karasawa, 1995), and which was designed to create the necessary appraisal conditions when anger was provoked (Batson et al., 2007; 2009). It is possible to distinguish moral outrage from personal anger by experimentally manipulating conditions relevant to the different appraisals (mistreatment of self and that of a stranger) and observing the resulting pattern of self-reported anger. According to Batson's proposition derived from an appraisal theory of emotion, it was assumed that moral outrage is elicited by the perception that another person's behavior has been morally wrong, while personal anger is elicited by the egoistic perception that the self (or an in-group member) has been undeservedly harmed. On the basis of this proposition, when participants are presented with an event including unfairness or immorality, we would find evidence of moral outrage if more anger is reported regardless of whether or not the person harmed is the self (or an in-group member). However, if more anger is reported only when the participants or their in-group members are harmed, then this would clearly be an evidence of personal anger.

To test this hypothesis, we focused on abduction as the moral violation presented to the participants because although there are many other types of moral violations, abduction can be considered as something more realistic in relation to the social issues. Therefore, it was assumed that compared to other violations, abduction would be more likely to be perceived as an extreme moral violation. Building on the method introduced by Batson et al. (2009) for differentiating moral outrage from personal anger through the manipulation of appraisal conditions, Japanese students were given a sealed envelope containing a fictitious newspaper article and a questionnaire during their classes. The cover story was a survey of public perception of newspapers. Participants were presented with one of two newspaper articles describing the abduction of either a Japanese or a Slovenian citizen, and were then asked to rate their feelings of anger and whether they found the abduction to be morally wrong. Their level of personal morality was then assessed.

\subsection{Predictions}

If anger evoked by witnessing an unfair or immoral act was personal, participants would report more anger only when the person abducted was Japanese, regardless of whether they identified themselves as more moral (i.e., an abductee main effect). However, if moral outrage is a conditional emotional reaction evoked only among those who identify themselves as more moral, then the response of personal anger would be found only among those scoring low on the questionnaire measure of morality: in other words, more anger would be reported by those scoring high in morality irrespective of the newspaper article that they had read, i.e., irrespective of the type of abductee (i.e., an abductee $\times$ morality interaction effect; 1 vs. 3 response patterns).

\section{Method}

\subsection{Participants}

The participants were Japanese undergraduate students at a private university. They were invited to participate collectively or individually. The 85 undergraduates who consented to participate (58 women and 27 men) were given an envelope containing a typewritten introduction, a newspaper article, and a questionnaire, and then asked to complete immediately. Their mean age was $18.84(S D=0.87)$.

\subsection{Procedure}

The cover story was entitled "Fact-Finding Survey on the Contents of a Newspaper Article and the Psychological Response of the Reader." The written introduction explained that the purpose of this survey was to ask participants to read a newspaper story and report the feelings and thoughts that story evoked in them after reading it. The introduction cautioned the following: (a) the article they were about to read had been checked in a thorough follow-up investigation, which confirmed that the case actually occurred; (b) the article had not yet been published in Japan; (c) each participant would be randomly assigned an article to read; (d) since the content of some articles may be shocking, they could stop reading immediately if they felt too upset; (e) the questionnaire was to be completed only after participants had read the article.

\subsubsection{Presentation of a Newspaper Story Describing a Case of Abduction}

Though the introduction explained that each participant would read a different article, they were randomly assigned an article regarding a case of abduction of either a Japanese or a Slovenian citizen. For half of the participants assigned to the Japanese abductee condition, the article carried the headline "Show Me The Way? Former Operative Discusses Abduction Activities." The article described a "former operative of the Democratic People's Republic of Korea" who admitted to abducting a "Japanese man" walking along a beach in the 
"Japanese Chugoku region" twenty-five years ago, now under investigation by the "Investigation Commission on Missing Japanese Probably Related to North Korea."

For half of the participants assigned to the Slovenian abductee condition, the article carried the headline "Show Me The Way? Former Anti-Government Organization Member Discusses Abduction Activities." The contents of the article were partially changed to describe a "former member of an anti-government organization" who admitted to abducting a "Slovenian man" walking along the beach in the "southern region of the Republic of Slovenia" twenty-five years ago, now under investigation by a "committee investigating citizens abducted by anti-government organizations." In this study, we chose a Slovenian as a fictitious abduction victim because Slovenia was deemed to be a nation to which Japanese participants were least likely to feel any sense of national ties or bond.

\subsubsection{Assessment of Anger after Reading about the Case of Abduction}

Immediately after reading the newspaper article, participants were randomly presented with a list of 16 adjectives describing different feelings and emotions. The list included nine adjectives that assessed feelings of anger (Batson et al., 2007; irritated, angry, upset, annoyed, offended, outraged, mad, perturbed, and frustrated) and seven filler adjectives (surprised, uninterested, frantic, tense, strange, calm, and pity). Participants were asked to indicate the degree to which they were feeling each emotion after reading the article on a 6-point scale ranging from 0 (not at all) to 5 (extremely).

\subsubsection{Assessment of the Perception of Abduction as Immorality}

For the measurement of whether participants judged the incident of abduction that they read about to be morally wrong, two items were originally developed. Participants were instructed that "We will now ask you about the incident describing in this article." They were then asked to rate, on a 6-point scale ranging from 0 (not at all) to 5 (totally), how morally wrong they thought the incident described in the article was and how immoral they thought the act described in this article was.

\subsubsection{Measuring Personal Morality}

To measure personal morality, we used single-item measures of the justice and care perspectives developed by Batson, Kobrynowicz, Dinnerstein, Kampf, and Wilson (1997), which tap the tendency to internalize the post-conventional and mature morality, respectively. Two different domains of morality, the justice and relationship-care perspectives have often been distinguished in past research (e.g., Gilligan, 1982). First, participants were asked to think about how they went about deciding on what they should do in social-conflict situations, such as a case wherein a friend who rarely attends class asks to borrow notes, when an accident-prone friend wants to borrow their car, or when friends want them to mediate an argument. They were then asked to rate, on a 6-point scale ranging from 0 (not at all) to 5 (totally), the extent to which each of the following perspectives reflects their thinking when trying to decide what they should do in a social conflict situation.

Participants were first presented with an account of the justice perspective, and asked to rate it on a 6-point scale.

One way to approach thinking about a social conflict is to see yourself in a process of deciding what is most just. This includes standing back from the problem at hand to consider the fairest way to resolve the dilemma. It often means invoking certain principles that you personally believe should govern the way people behave. The problem, as you perceive it involves competing sets of values. You seek what is most just by considering the rights of all involved.

They were then presented with an account of the relationship-care perspective, and asked to rate it on a 6-point scale.

One way to approach thinking about a social conflict is to see yourself involved in relationship with others. This means you have certain responsibilities to be concerned for others and consider how and what you do will help or hurt those involved. Conflicts are considered in the context of their effect on the relationships between people, and whether those relationships will be maintained, restored, or damaged. You seek a way to respond that will minimize the hurt to all involved.

\subsubsection{Debriefing}

After collecting the envelopes containing the questionnaires and article, the experimenter explained the true purpose of the research and all the deception by handing out a typewritten description of the study. During debriefing, none of the participants expressed doubt about the newspaper story. After debriefing, the experimenter thanked and appreciated participants for their time. 


\section{Results}

Forty-two participants read the newspaper story describing a case of abduction of a Japanese citizen, and remaining 43 participants read the story of abduction of a Slovenian citizen. Since gender differences had no significant effect on the dependent variables, the following analyses are collapsed across gender.

\subsection{Justice and Relationship-Care Perspectives}

The mean scores for the justice and relationship-care perspectives were $M=2.79$ and 3.52, respectively. These means are well above the midpoint (2.50) of the scale for each measure, indicating that on average, the participants identified themselves to be quite moral. Although weak, a significant positive correlation, $r(83)$ $=.22, p<.05$, between them suggests that the justice and relationship-care perspectives are not independent but rather tend to mirror one another. However, our participants preferred the relationship-care perspective to the justice perspective, $t(84)=4.02, p<.001, d=0.55$, suggesting that if anything, the aspects of self-reported personal morality analyzed in this study reflect relationship-care more closely than justice.

To identify participants who were low and high in self-reported morality, we divided them into two groups using median splits for each of the two morality types: the $n$ of the high self-reported justice group was 50 and that of the low self-reported justice group was 35 , while the $n$ of the high self-reported relationship-care group was 51 and that of the low self-reported relationship-care group was 34 .

\subsection{Perception of the Immorality of the Abduction}

We averaged the scores for two perceived immorality items to create an index of perception of immorality (Cronbach's $\alpha=.65$ ). To examine the effect of abductee type and level of self-reported morality on whether participants judged the abduction article they read to be morally wrong, we conducted an analysis of variance (ANOVA) for justice and relationship-care perspective variables. For the justice perspective, ANOVA with abductee type (2) and justice perspective (2) as between-participants variables revealed that there were no significant effects on the perception of immorality, $0.00<F \mathrm{~s}<2.34, p \mathrm{~s}>.13$. As can be seen in the upper left of Table 1, the abduction of a Slovenian citizen was clearly thought to be morally wrong, much like the abduction of a Japanese citizen, regardless of the level of self-reported justice perspective.

For the relationship-care perspective, we performed a 2 (abductee type) $\times 2$ (relationship-care perspective) ANOVA on the perception of immorality. Both independent variables are between-participants. The results revealed that there were no significant differences across conditions, $1.50<F \mathrm{~s}<2.31, p \mathrm{~s}>.13$, meaning that the abduction was judged extremely morally wrong in all conditions (see the lower left of Table 1).

Table 1. Means and standard deviations for perception of immorality and reported anger after reading about a case of abduction

\begin{tabular}{llc}
\hline & \multicolumn{2}{c}{ Dependent measure } \\
\cline { 2 - 3 } Condition & & Pnger \\
\hline Japanese abductee & $4.39(0.80)$ & $2.94(1.18)$ \\
$\quad$ High self-reported justice perspective & $4.50(0.69)$ & $2.83(1.12)$ \\
$\quad$ Low self-reported justice perspective & & \\
Slovenian abductee & $4.22(0.76)$ & $2.22(1.04)$ \\
$\quad$ High self-reported justice perspective & $4.13(0.99)$ & $1.92(1.38)$ \\
$\quad$ Low self-reported justice perspective & & \\
\hline Japanese abductee & $4.65(0.65)$ & $2.95(1.34)$ \\
$\quad$ High self-reported relationship-care perspective & $4.17(0.79)$ & $2.81(0.84)$ \\
$\quad$ Low self-reported relationship-care perspective & & \\
Slovenian abductee & $4.17(0.72)$ & $2.08(1.30)$ \\
$\quad$ High self-reported relationship-care perspective & $4.22(1.05)$ & $2.16(0.96)$ \\
$\quad$ Low self-reported relationship-care perspective &
\end{tabular}

Note: $N=85$. Perception of immorality was assessed by the two items (e.g., How morally wrong you thought the incident described in this article was?). Anger was assessed by nine adjectives related to anger (e.g., irritated, angry, and annoyed). The response scale for each measure was 0 to 5 . The numbers in parentheses are standard deviations. 


\subsection{Anger at Abduction}

We created an index of anger by averaging the score for the nine anger adjectives (Cronbach's $\alpha=.91$ ). To assess the anger felt after reading about the abduction, we conducted the same statistical procedures for the anger index, as for the perceived immorality index. For the justice perspective, a 2 (abductee type) $\times 2$ (justice perspective) ANOVA revealed only a significant main effect of abductee type on anger, $F(1,81)=10.06, p<.01$, $\eta^{2}=.11$. As can be seen in the upper right of Table 1, participants reported more anger after reading about the abduction of a Japanese citizen $(M=2.89)$ than a Slovenian citizen $(M=2.07)$, regardless of whether the level of self-reported justice perspective was low or high.

For the relationship-care perspective, the 2 (abductee type) $\times 2$ (relationship-care perspective) ANOVA revealed a similar pattern of significant main effect of abductee type as using the justice perspective, $F(1,81)=8.66, p$ $<.01, \eta^{2}=.10$. The lower right of Table 1 shows that more anger was reported in the Japanese abductee condition $(M=2.88)$ than in the Slovenian abductee condition $(M=2.12)$ regardless of whether the self-reported relationship-care perspective score was low or high. Neither the main effect of the relationship-care perspective nor the interaction approached significance.

\subsection{Regression of Perception of Immorality and Anger by Abductees Type and Personal Morality}

To confirm that the results were not a statistical artifact of having converted the justice and relationship-care perspective index to discrete variables (by median splits), we performed four types of hierarchical regression analysis, with the abductee type (dummy variable; a Japanese abductee $=1$, a Slovenian abductee $=-1$ ), and the two types of personal morality (continuous variable) as independent variables, and perception of immorality and anger as dependent variables (see Table 2). To minimize multicollinearity due to a high correlation between the independent variables, the independent variables were standardized within each participant.

Table 2. Hierarchical regression of perception of immorality and anger by abductee type and personal morality

\begin{tabular}{|c|c|c|c|c|}
\hline & \multicolumn{2}{|c|}{ Perception of immorality } & \multicolumn{2}{|c|}{ Anger } \\
\hline & Model 1 & Model 2 & Model 1 & Model 2 \\
\hline & \multicolumn{4}{|c|}{ Justice perspective } \\
\hline Abductee type & $0.13(.16)$ & $0.13(.16)$ & $0.42^{* *}(.35)$ & $0.42^{* *}(.35)$ \\
\hline Justice perspective & $0.02(.03)$ & $0.02(.03)$ & $0.16 \quad(.13)$ & $0.17 \quad(.14)$ \\
\hline Adjusted $R^{2}$ & .00 & \multicolumn{3}{|c|}{$.10^{* *}$} \\
\hline Abductee type $\times$ Justice perspective & \multicolumn{3}{|c|}{$-0.01(-.02)$} & $0.04 \quad(.03)$ \\
\hline Adjusted $R^{2} / \Delta R^{2}$ & \multicolumn{3}{|c|}{$.00 / .00$} & $.10^{* *} / .00$ \\
\hline$F$ & 1.10 & 0.74 & $5.73^{* *}$ & $3.81^{*}$ \\
\hline & \multicolumn{4}{|c|}{ Relationship-care perspective } \\
\hline Abductee type & $0.14(.17)$ & $0.14(.17)$ & $0.40^{* *}(.33)$ & $0.40^{* *}(.33)$ \\
\hline Relationship-care perspective & $0.12(.14)$ & $0.11(.14)$ & $0.02 \quad(.01)$ & $0.02 \quad(.01)$ \\
\hline Adjusted $R^{2}$ & .02 & \multicolumn{3}{|c|}{$.08^{* *}$} \\
\hline $\begin{array}{l}\text { Abductee type } \times \text { Relationship-care } \\
\text { perspective }\end{array}$ & \multicolumn{3}{|c|}{$0.03(.04)$} & $-0.01(-.01)$ \\
\hline Adjusted $R^{2} / \Delta R^{2}$ & \multicolumn{3}{|c|}{$.02 / .00$} & $.08^{* *} / .00$ \\
\hline$F$ & 1.97 & 1.34 & $4.82^{* *}$ & $3.18^{*}$ \\
\hline
\end{tabular}

Note: The coefficients in parentheses are $\beta$ s.

$* p<.05 . * * p<.01$.

In the hierarchical regression analysis of perception of immorality by abductee type and justice perspective, neither the main effect of abductee type nor that of justice perspective approached significance, $b=0.13, t(82)=$ $1.49, p>.14 ; b=0.02,|t|(82)<1.00, p>.80$, respectively, and the variance accounted for $\left(R^{2}\right)$ was not 
significantly increased when the abductee type $\times$ justice perspective interaction was added to regression model, $\Delta R^{2}=.00, p>.87$. The same procedure was repeated for the analysis using the relationship-care perspective as independent variable. Again, neither the main effect of abductee type nor that of the relationship-care perspective were significant, $b=0.14, t(82)=1.58, p>.12 ; b=0.12, t(82)=1.32, p>.18$, respectively, and the abductee type $\times$ relationship-care perspective interaction did not produce a significant increment of $R^{2}, \Delta R^{2}=.00, p>.73$.

In the regression of anger by abductee type and justice perspective, on the other hand, it was found that the main effect of abductee type was significant, $b=0.42, t(82)=3.30, p<.01$, while the increment of $R^{2}$ after adding the abductee type $\times$ justice perspective interaction did not approach significance, $\Delta R^{2}=.00, p>.77$. Reported anger was significantly increased when reading about the abduction of a Japanese citizen relative to the abduction of a Slovenian citizen. Using the relationship-care perspective as the independent variable in this analysis produced a similar pattern of results: the main effect of abductee type on anger was significant, $b=0.40, t(82)=3.10, p$ $<.01$, but $R^{2}$ was not significantly increased when the abductee type $\times$ relationship-care perspective interaction was entered into the regression equation, $\Delta R^{2}=.00, p>.91$. This means that participants who read about the abduction of a Japanese citizen were far more likely to feel anger than those who read about the abduction of a Slovenian citizen. The main effects of the justice and relationship-care perspectives were both nonsignificant, $b$ $=0.16, t(82)=1.28, p>.20 ; b=0.02,|t|(82)<1.00, p>.90$, respectively.

Given that the results using the regression analysis correspond exactly to the those using ANOVA, it was demonstrated that the response patterns for perceived immorality and anger were not caused by having conducted median splits on the two morality types.

\section{Discussion}

The present research attempted to examine the effect of personal morality on whether moral outrage is evoked following reading about a case of abduction.

\subsection{Does Personal Morality Elicit Moral Outrage?}

The results of the ANOVA on perception of immorality showed similar response styles across conditions. As can be seen in the upper and lower left of Table 1, the abduction was judged morally wrong in all conditions, indicating a ceiling effect ( $M$ ranging from 4.13 to 4.65 , on a scale of 0 to 5). These findings reflect the fact that both those scoring low and high in self-reported morality thought abduction were clearly morally wrong regardless of whether the person abducted was Japanese or Slovenian.

However, a different pattern of the results is seen in the ANOVA on anger, which showed that differences among some conditions approached significance. Only a main effect of abductee type was significant (see in the upper and lower right of Table 1), meaning that participants in the Japanese abductee condition reported feeling more anger than did the participants in the Slovenian abductee condition, irrespective of the level of self-reported morality. This difference in anger was found even though abduction was judged to be morally wrong. Given these response patterns, our findings seem to suggest that the anger felt in response to abduction is personal anger - that is, anger elicited by egoistic concern - rather than moral outrage. Moreover, we initially regarded personal morality as the significant dispositional determinant producing moral outrage. However, since the present results indicate that the effect of abductee type on anger did not depend on the level of both either the justice or relationship-care perspectives, we conclude that moral outrage is unlikely to being provoked even among individuals high in morality.

\subsection{Why Was Evidence of Moral Outrage Not Found?}

So why was evidence of moral outrage not found in our study, like past research? Focusing on the personality measure adopted in the present research, one possible reason could be the validity of the measures of the justice and relationship-care perspectives. According to certain researchers, an individual's internalized moral or ethical values cannot be empirically measured; even if we were to assume that they were measurable, it was implied that whatever measurable elements there were, they would merely be a tendency toward having a phony sense of morality rather than having authentic sense of morality (Batson et al., 1997). The lack of evidence of moral outrage may be because of the low validity of these measures. However, neither the correlation of the perception of immorally index with the justice perspective nor that with the relationship-care perspective were significant, $r(83)=.08, p>.47 ; r(83)=-.01, p>.91$, respectively, indicating that those high in morality did not necessarily emphasize - or appeal against - the injustice of the abduction. Therefore, there is unlikely to be a problem in measuring either the justice or the relationship-care perspective, at least in the present study.

Second, it is possible that moral outrage may just be a rhetorical phrase used to justify revenge or vengeance, and that only personal anger may be evoked when witnessing (or experiencing) a moral violation. The fact that the 
evidence of moral outrage is so hard to find may stem from the nonexistence of moral outrage itself. However, if this is true, why do people tend to talk about moral outrage and believe that moral outrage should produce behavior intended to restore fairness? One possible reason is that the victim's role is assigned according to the harm done to an individual. According to some researchers, when people are harmed, they behave in an egotistic manner because they feel entitled to be treated tolerantly, such as receiving positive outcomes (or avoiding negative outcomes), being granted favors, or reduction of personal burdens. This is known as victim entitlement (Zitek, Jordan, Monin, \& Leach, 2010). On the basis of this finding, individuals may experience a sense of entitlement to right the wrong when undeservedly harmed, and therefore, they may feel as though they possess privileged positions. In turn, they may regard themselves as having earned the right to be free from self-restraint or allowed to take revenge, and by this justification, personal anger may be seen as moral outrage, albeit less consciously. This specific biased cognition providing justification for personal anger may cause us to believe in the existence of moral outrage. However, while this interpretation is suggested as an explanation of the failure to find evidence of moral outrage, it is not a strong enough reason to deny the existence of moral outrage because some studies have reported empirical evidence reflecting traces of moral outrage (Chow, Tiedens, \& Govan, 2008, Study 2; Turillo, Folger, Lavelle, Umphress, \& Gee, 2002).

\subsection{Limitations and Conclusion}

Although we concluded from our results that personal anger is a prevalent and powerful emotion when witnessing or experiencing a moral violation, we are not in the position to generalize our findings because of several methodological limitations. A first limitation was indicated by Batson et al. (2009), namely the fact that no control condition was incorporated. In the present study, we adopted his experimental paradigm in which participants read a fictitious newspaper article. While this paradigm has the advantage of having participants perceive immorality without harming them directly, it is ecologically difficult to create a condition with a parallel story in which no abduction occurred (i.e., in which no moral violation occurred), meaning that the baseline level of anger response when no moral standard was violated is ambiguous. Therefore, we cannot rule out the possibility that a lower level of anger reported in the Slovenian abductee condition may not have resulted simply from error, but may have reflected moral outrage. Future research should include a control condition.

The second limitation that any future research must address is the type of violation. Our study showed that the immoral act of abduction did not evoke moral outrage, but did not analyze whether this finding applies to other immoral acts. Therefore, the conclusion that evidence of moral outrage was not found applies only to one moral violation, i.e., abduction. In other words, there still remains a possibility that moral outrage may be evoked by other immoral acts. Future research should consider re-examining whether only personal anger is evoked in response to other violations.

Finally, the fact that the participants in this study were Japanese university students may be an additional reason why moral outrage was not found. In general, most of the university students frequently interact with people close to them, such as their family and friends, and they have few formal contact with people, as they might be in a business setting. According to research focused on anger and interpersonal relationships, it was found that Japanese students experienced anger motivated by self-interest towards people close to them, such as family and friends (Uehara, Nakagawa, Mori, \& Ohbuchi, 2012). In light of this finding, since Japanese student participants already have a high propensity for selfish anger, we can speculate that when faced with an event that included unjust harm, they would naturally more easily provoke anger consistent with such propensity. In other words, there is a possibility that the personal anger identified by our study is actually a carry-over product of the anger Japanese university students experience on a daily basis. The variables that measure the frequency of experiencing selfish anger, or using a large sample that includes adults, will be keys in the examination forward with further research.

In sum, the present study revealed that even among individuals high in morality, anger expressed by witnessing an immoral act is personal anger at harm done to the self or in-group members, not moral outrage at the violation of moral standards per se. It is implied that these egoistic psychological mechanisms not only make fairness or justice difficult to restore but also indicate that righteous anger labeled moral outrage may be the product of a type of anger in which people feel justified.

\section{References}

Barclay, L. J., Skarlicki, D. P., \& Pugh, S. D. (2005). Exploring the role of emotions in injustice perceptions and retaliation. Journal of Applied Psychology, 90, 629-643. http://dx.doi.org/10.1037/0021-9010.90.4.629

Batson, C. D., Chao, M. C., \& Givens, J. M. (2009). Pursuing moral outrage: Anger at torture. Journal of Experimental Social Psychology, 45, 155-160. http://dx.doi.org/10.1016/j.jesp.2008.07.017 
Batson, C. D., Kennedy, C. L., Nord, L.-A., Stocks, E. L., Fleming, D. A., Marzette, C. M., ... \& Zerger, T. (2007). Anger at unfairness: Is it moral outrage? European Journal of Social Psychology, 37, 1272-1285. http://dx.doi.org/10.1002/ejsp.434

Batson, C. D., Kobrynowicz, D., Dinnerstein, J. L., Kampf, H. C., \& Wilson, A. D. (1997). In a very different voice: Unmasking moral hypocrisy. Journal of Personality and Social Psychology, 72, 1335-1348. http://dx.doi.org/10.1037/0022-3514.72.6.1335

Chow, R. M., Tiedens, L. Z., \& Govan, C. L. (2008). Excluded emotions: The role of anger in antisocial responses to ostracism. Journal of Experimental Social Psychology, 44, 896-903. http://dx.doi.org/10.1016/j.jesp.2007.09.004

Correia, I., \& Vala, J. (2003). When will a victim be secondarily victimized? The effect of observer's belief in a just world, victim's innocence and persistence of suffering. Social Justice Research, 16, 379-400. http://dx.doi.org/10.1023/A:1026313716185

Darley, J. M., \& Pittman, T. S. (2003). The psychology of compensatory and retributive justice. Personality and Social Psychology Review, 7, 324-336. http://dx.doi.org/10.1207/S15327957PSPR0704_05

de Rivera, J., Gerstmann, E., \& Maisels, L. (2002). Acting righteously: The influence of attitude, moral responsibility, and emotional involvement. In M. Ross, \& D. T. Miller (Eds.), The justice motive in everyday life (pp. 271-288). New York: Cambridge University Press.

Fetchenhauer, D., \& Huang, X. (2004). Justice sensitivity and distributive decisions in experimental games. Personality and Individual Differences, 36, 1015-1029. http://dx.doi.org/10.1016/S0191-8869(03)00197-1

Forgas, J. P. (1992). Affect in social judgments and decisions: A multiprocess model. In M. P. Zanna (Ed.), Advances in experimental social psychology (Vol. 25, pp. 227-275). New York: Academic Press.

Gilligan, C. (1982). In a different voice: Psychological theory and women's development. Cambridge, MA: Harvard University Press.

Heider, F. (1958). The psychology of interpersonal relations. Hillsdale, NJ: Lawrence Erlbaum Associates.

Hoffman, M. L. (1987). The contribution of empathy to justice and moral judgment. In N. Eisenberg, \& J. Strayer (Eds.), Empathy and its development (pp. 47-80). New York: Cambridge University Press.

Karasawa, K. (1995). Cognitive antecedents of emotions: Findings and future directions. Japanese Psychological Research, 37, 40-55. http://dx.doi.org/10.4992/psycholres1954.37.40

Latané, B., \& Darley, J. M. (1970). The unresponsive bystander: Why doesn't he help? New York: Appleton-Century-Crofts.

Lieberman, D., \& Linke, L. (2007). The effect of social category on third party punishment. Evolutionary Psychology, 5, 289-305.

Mohiyeddini, C., \& Schmitt, M. (1997). Sensitivity to befallen injustice and reactions to unfair treatment in a laboratory situation. Social Justice Research, 10, 333-353. http://dx.doi.org/10.1007/BF02683307

O’Mara, E. M., Jackson, L. E., Batson, C. D., \& Gaertner, L. (2011). Will moral outrage stand up? Distinguishing among emotional reactions to a moral violation. European Journal of Social Psychology, 41, 173-179. http://dx.doi.org/10.1002/ejsp.754

Schmitt, M., \& Dörfel, M. (1999). Procedural injustice at work, justice sensitivity, job satisfaction and psychosomatic well-being. European Journal of Social Psychology, 29, 443-453. http://dx.doi.org/10.1002/(SICI)1099-0992(199906)29:4<443::AID-EJSP935>3.0.CO;2-C

Schmitt, M., \& Mohiyeddini, C. (1996). Sensitivity to befallen injustice and reactions to a real-life disadvantage. Social Justice Research, 9, 223-238. http://dx.doi.org/10.1007/BF02197249

Schmitt, M., Neumann, R., \& Montada, L. (1995). Dispositional sensitivity to befallen injustice. Social Justice Research, 8, 385-407. http://dx.doi.org/10.1007/BF02334713

Tetlock, P. E., Kristel, O. V., Elson, S. B., Green, M. C., \& Lerner, J. S. (2000). The psychology of the unthinkable: Taboo trade-offs, forbidden base rates, and heretical counterfactuals. Journal of Personality and Social Psychology, 78, 853-870. http://dx.doi.org/10.1037/0022-3514.78.5.853

Tsang, J. (2002). Moral rationalization and the integration of situational factors and psychological processes in immoral behavior. Review of General Psychology, 6, 25-50. http://dx.doi.org/10.1037//1089-2680.6.1.25 
Turillo, C. J., Folger, R., Lavelle, J. J., Umphress, E. E., \& Gee, J. O. (2002). Is virtue its own reward? Self-sacrificial decisions for the sake of fairness. Organizational Behavior and Human Decision Processes, 89, 839-865. http://dx.doi.org/10.1016/S0749-5978(02)00032-8

Uehara, S., Nakagawa, T., Mori, T., \& Ohbuchi, K. (2012). When does anger evoke self-interest and fairness motives? The moderating effects of perceived responsibility for needs. Japanese Psychological Research, 54, 137-149. http://dx.doi.org/10.1111/j.1468-5884.2011.00501.x

Zitek, E. M., Jordan, A. H., Monin, J. B., \& Leach, F. R. (2010). Victim entitlement to behave selfishly. Journal of Personality and Social Psychology, 98, 245-255. http://dx.doi.org/10.1037/a0017168

\section{Copyrights}

Copyright for this article is retained by the author(s), with first publication rights granted to the journal.

This is an open-access article distributed under the terms and conditions of the Creative Commons Attribution license (http://creativecommons.org/licenses/by/3.0/). 